\title{
Trabalhadores a ver navios: reflexões sobre o mercado de trabalho na indústria naval na Região Metropolitana do Rio de Janeiro
}

Workers left in the lurch: thoughts on the shipbuilding labor market in the Rio de Janeiro Metropolitan Area

Claudiana Guedes de Jesus Robson Dias da Silva

\section{Resumo}

Este artigo analisa a importância da região metropolitana do Rio de Janeiro no mercado de trabalho da indústria de construção naval brasileira, especialmente as cidades do Rio de Janeiro, $\mathrm{Ni}$ terói e São Gonçalo. Destaca a desconcentração regional da indústria naval e a evolução do emprego nas diferentes fases de sua história, com foco no período recente de início de uma provável nova crise, além de caracterização do mercado de trabalho e descrição de uma provável nova crise a partir de 2014 nessa indústria. A produção naval brasileira sempre foi concentrada no Sudeste, em especial no estado do Rio de Janeiro, berço do setor, historicamente detentor dos principais estaleiros e dos principais indicadores de produção e emprego.

Palavras-chave: indústria de construção naval; trabalho; região metropolitana; Rio de Janeiro; desconcentração regional.

\begin{abstract}
This papers aims to analyze the importance of the metropolitan area of Rio de Janeiro in the Brazilian shipbuilding labor market, especially the cities of Rio de Janeiro, Niterói and São Gonçalo. It highlights the regional decentralization of the shipbuilding industry and the evolution of employment in different stages of its history, and focus on the recent period in which a new crisis has probably been triggered. In addition, the article characterizes the labor market and describes the probable new crisis that has been affecting this industry since 2014. The Brazilian shipbuilding production has always been concentrated in the Southeast, especially in the state of Rio de Janeiro, which has historically housed the main shipyards and the main output and employment indicators.
\end{abstract}

Keywords: shipbuilding industry; labor; metropolitan area; Rio de Janeiro; regional decentralization. 


\section{Introdução}

Este artigo analisa a importância da Região Metropolitana do Rio de Janeiro (RMRJ) para o mercado de trabalho da indústria de construção naval brasileira, precisamente os municípios de Rio de Janeiro, Niterói e São Gonçalo. A elaboração deste estudo foi conduzida destacando-se o processo de desconcentração regional da indústria naval brasileira, ensejada por políticas setoriais específicas, e a evolução histórica do estoque de postos de trabalho, com foco especial no período mais recente, quando se observa o início de uma nova crise para o setor. Para tanto, descrevemos as principais características do mercado de trabalho na indústria naval, os principais pontos no desenvolvimento dinâmico e cíclico da construção naval no Brasil e as consequências para o volume de emprego, tudo a partir da perspectiva do desenvolvimento urbano metropolitano fluminense.

Devemos assinalar que, quando tratamos de desconcentração regional, estamos aludindo ao processo de maior distribuição espacial da produção naval brasileira para outros estados/municípios que não tinham tradição nessa atividade. Assim, a partir de fins dos anos 1990, observamos a implantação de novos estaleiros em estados nos quais não havia plantas navais de grande porte. Importante lembrar que a produção dessa indústria sempre esteve muito concentrada na região Sudeste do País, em especial no estado do Rio de Janeiro, berço do setor e detentor histórico das principais plantas produtivas e, por conseguinte, o mais importante espaço nacional para os indicadores de produção e emprego setoriais.
De maneira sucinta, a indústria de construção naval brasileira passou por quatro fases em seu desenvolvimento: a) entre a década de 1960 a meados dos 1980: estruturação/consolidação da indústria no País, com destaque para o ano de 1979 quando o País ocupou o segundo lugar mundial na indústria; ${ }^{1}$ b) de meados dos 1980 a meados dos 1990: primeira grande crise na construção naval no País com diminuição da produção, fechamento de estaleiros e desemprego; c) de 1997 a 2014: retomada das atividades da indústria com políticas direcionadas $^{2}$ e grandes investimentos, aberturas de novos plantas produtivas e desconcentração regional; e d) a partir de 2015: início de nova crise para a indústria, com diminuição de produção e emprego e fechamento de estaleiros.

Independentemente dos seus altos e baixos, a indústria naval brasileira tem destacada importância no cenário internacional. Desde o princípio do século XXI, o Brasil teve um esforço para reativar as atividades do setor, fato que trouxe consequências positivas para sua posição no cenário mundial. A carteira de encomendas dos estaleiros internacionais listou 0 Brasil entre os dez maiores construtores, considerando navios e plataformas (Clarksons apud SIN/Sinaval, 2014).

Desde a década de 1960, os países asiáticos veem dominando o mapa da produção naval mundial. China, Coreia do Sul e Japão ocupam os primeiros lugares do ranking internacional e juntos são responsáveis por mais de $80 \%$ das encomendas globais. Mesmo na escala internacional, há forte concentração, visto que a China domina o mercado de navios graneleiros de grande porte, avançando também na construção de petroleiros. Em segundo, 
a Coreia do Sul, líder na construção de navios petroleiros, atuando na construção de porta-contêineres e navios gaseiros. Por fim, o Japão destacando-se na construção de navios especializados, gaseiros e porta-contêineres. Deve-se registrar que, no sudeste asiático, ainda há Cingapura, líder na produção de plataformas de produção de petróleo e sondas de perfuração (Unctad, 2014).

Voltando ao caso brasileiro, é importante assinalar que, para fins deste artigo, a indústria de construção naval é entendida como o conjunto formado pelos estaleiros navais de grande e médio porte (Quadros 2 e 3). ${ }^{3}$ Na cadeia produtiva naval, os estaleiros são os responsáveis por construção e montagem de embarcações, possuem complexo processo produtivo e são fornecedores de bens de capital contratados por encomenda.

Em termos metodológicos, o artigo se baseou em pesquisa qualitativa, estruturada a partir de revisão de literatura, bem como em análise de dados secundários, especialmente de duas fontes oficiais: a Relação Anual de Informações Sociais base estatística do Ministério do Emprego e Trabalho - Rais/MTE e do Sindicato Nacional da Indústria de Construção Naval e Offshore - Sinaval. A Rais/MTE foi a principal base para informações sobre os trabalhadores do setor. 0 período em análise de estende de 2006 a 2014, e todos os atributos descrevem a situação dos detentores de vínculo em 31/12 do respectivo ano. ${ }^{4}$ Também foram utilizados dados históricos da indústria naval elaborados pelo Sindicato Nacional da Indústria de Construção Naval e Offshore - Sinaval. 0 sindicato, através de sua assessoria de impressa, faz pesquisas anuais com base em entrevistas com os estaleiros que são seus associados e as divulga através de suas publicações periódicas.

Para tanto, este artigo está estruturado em cinco partes com essa apresentação. Primeiramente, analisamos as condições do mercado de trabalho na Indústria Naval Brasileira, destacando suas principais características e a evolução, em perspectivas de mais longo prazo. Em seguida, apresentamos dados que revelam a importância da Região Metroplitana do Rio de Janeiro para a dinâmica do mercado de trabalho setorial nacional, mas também à dinâmica urbana metropolitana fluminense como um todo, tendo em mente que o emprego é variável-chave para o bem-estar e urbanização inclusiva da classe trabalhadora, além do destaque do processo de desconcentração regional da indústria. Posteriormente, descrição dos desafios contemporanêos no mercado de trabalho da indústria naval no País no momento atual, em especial a situação da Região Metropolitana do Rio de Janeiro. Para finalizar, listamos algumas considerações finais com principais pontos resultados da pesquisa desenvolvida para este estudo.

\section{0 mercado de trabalho na indústria naval brasileira: características e evolução}

0 entendimento das características do trabaIho na indústria de construção naval passa pela análise de seu processo produtivo, em muito determinado pelo diferente funcionamento: a saber, sua inserção no mercado se dá enquanto fornecedora de bens de capital por encomenda, o que resulta no forte comportamento 
cíclico observado em sua trajetória expansiva. Por exemplo, a contratação de produtos/obras, em sua maioria, de longo prazo de maturação, leva à inconstância em suas atividades, resultando em alternância entre momentos de alta capacidade ociosa e de forte utilização da capacidade instalada. ${ }^{5}$

Dois outros pontos devem ser apontados como grandes características da indústria de construção naval: o fato de ser capital intensiva e de possuir fortes barreiras à entrada. É uma indústria fabricante de produtos complexos, de grande porte físico, alto custo financeiro, tempo de produção elevado e produção de poucas unidades por ano. De acordo com Marins (2009), a demanda de construção de navios alterna períodos de grande quantidade de encomendas e expansão da produção, com períodos de poucas encomendas e retração da capacidade produtiva agregada. Destaca que esse tipo de comportamento da demanda é comum em outros tipos de indústria de bens de capital, como é o caso da indústria aeronáutica. Como destacado por Coutinho, Sabbatini e Ruas (2006, p. 22), é uma indústria especulativa, fornecedora de bens de capital sob encomenda, em que o lag temporal entre a contratação e a entrega final é quase sempre superior a 24 meses, o que a torna, portanto, sujeita ao comportamento cíclico de preços de insumos de produção e fretes.

Na construção naval, os custos fixos são muito elevados, reforçando a necessidade de utilização constante da capacidade produtiva. Ou seja, há sempre saltos descontínuos de oferta, o que resulta na imposição de igualmente elevadas barreiras à saída, reforçando o caráter cíclico dos preços. Além disso, esses elevados custos fixos aliados às altas barreiras à saída contribuem para acirrar a competição entre os estaleiros (ibid.).

Em relação à organização da produção, o setor é, de modo geral, orientado à fabricação de projetos únicos com estruturas que são (des)mobilizadas com o propósito de executar um único projeto. Ademais, possui alta complexidade em instalações industriais fixas e grande volume de recursos alocados na implantação da infraestrutura produtiva.

0 modelo de organização da produção empregado no início da década de 1960 se caracterizava pela fabricação e montagem de peça por peça na carreira ou no dique do estaleiro. ${ }^{6}$ Esse modelo, que se aproxima de um canteiro de obras, requeria mais baixos investimentos, capacidade de movimentação de carga e nível de mecanização (Marins, 2009, p. 12). ${ }^{7}$

Atualmente, a produção de um navio de grande porte não é realizada propriamente em uma linha de produção. A produção naval utiliza o conceito de Tecnologia de Grupo segundo o qual a sequência de trabalho é realizada em oficinas com máquinas e pessoal específicos. Os navios são normalmente construídos em blocos ou anéis porque, geralmente, há limitações de espaço físico próximo ao mar (Negri, Kubota e Turchi, 2009, p. 47).

Vale destacar que a indústria naval possui elevada dependência de políticas de Estado, notadamente em relação ao financiamento e à geração de demanda. Não se pode desconsiderar que a importância estatal também se verifica por meio de instrumentos de incentivos e regulação, como subsídios, reservas de mercado, benefícios fiscais e proteção à cabotagem, entre outros. As razões para tal dependência estão associadas a segurança nacional, falhas de mercado e efeitos gerados pela indústria 
naval nos demais segmentos econômicos. A dependência de políticas específicas pode ser percebida em todos os países líderes da indústria no mundo e no Brasil (Jesus, 2013).

Por outro lado, o setor requer rigorosos controles de qualidade que são regulados por organismos internacionais de certificação (entidades ou sociedades classificadas), bem como por regulamentos internacionais estabelecidos em matéria de segurança dos transportes marítimos. ${ }^{8}$ Refletindo a partir da perspectiva da "cadeia produtiva setorial", devemos ressaltar que cada vez mais os estaleiros estão exercendo o papel de montadores de embarcações, ocupando a posição de elo central da cadeia, dependendo muito, à montante, dos fornecedores, em especial da indústria siderúrgica, indústria de navipeças e de escritórios de projetos; e, à jusante, dos armadores e das sociedades certificadoras e classificadoras. ${ }^{9}$ Por conseguinte, possuem grande potencial de geração de emprego, utilizam mão de obra altamente qualificada, e a produção exige várias especializações. Essa versatilidade do pessoal ocupado é, em grande medida, devido à complexidade inerente e peculiar de seu processo, sendo necessário destacar que, além da formação técnica, a experiência adquirida no trabalho (learning by doing) também é fator essencial (ibid.).

Historicamente, a evolução do volume de emprego dos trabalhadores navais no Brasil pode ser dividida em quatro momentos distintos resultados do próprio desenvolvimento cíclico do setor no País. Primeiramente, de meados da década de 1950 até início da década de 1980, tivemos a fase que identificamos como da estruturação/desenvolvimento e auge, quando o Brasil teve o segundo maior parque naval mundial, atrás apenas do Japão, em volume de processamento de aço. Posteriormente, nas décadas de 1980 e 1990, ocorreu período de crise da indústria de construção naval, com a forte diminuição da produção, do emprego e com o fechamento de grande parte dos estaleiros.

Na terceira fase, com início em fins do século XX (1997-2014), observamos um momento denominado, por muitos estudiosos, retomada da indústria naval brasileira com fortes investimentos e crescimento do emprego com destaque para o forte empenho do governo federal nesse projeto. Novo quadro devido muito à exploração de petróleo offshore com intenso aumento de contratações de serviços de embarcações de apoio marítimo. E, por fim, o momento atual, iniciado em 2015, com grande retração de investimentos, diminuição das encomendas e do apoio do estatal do governo federal. Além da diminuição de demandas da Trasnpetro/Petrobras concomitante aos problemas financeiros da Sete Brasil. ${ }^{10} 0$ quadro e as prospectivas dessa nova fase, apesar de cedo para uma definição, levam para uma nova crise no setor no Brasil (Quadro 1).

A evolução no número de trabalhadores corrobora as transformações do setor no País, como pode ser observado no Gráfico 1, que traz o volume de emprego naval desde os anos 1960. Nesta década, existiam pouco mais de mil trabalhadores navais no País, chegando ao máximo histórico até então, em 1979, pouco mais de 39 mil. Depois desse significativo crescimento que marcou a consolidação do setor, ocorreu, a partir de meados da década de 1980, a primeira e grande crise na indústria naval brasileira: diminuição das atividades e fechamento de estaleiros e consequente aumento constante do desemprego. 


\section{Quadro 1 - As quatro fases de desenvolvimento da Indústria Naval no Brasil - $1950 / 2016$}

\begin{tabular}{|c|c|c|c|c|}
\hline $\begin{array}{c}\text { Fases da } \\
\text { indústria } \\
\text { naval brasil }\end{array}$ & $\begin{array}{c}\text { Estruturação, } \\
\text { expansão e auge histórico }\end{array}$ & Primeira grande crise & Retomada & Crise? \\
\hline Períodos & $\begin{array}{c}\text { Anos } 1950 \text { e meados dos } \\
\text { anos } 1980\end{array}$ & $\begin{array}{c}\text { Meados dos anos } 1980 \\
\text { E } 1990\end{array}$ & $1997-2014$ & Pós-2015 \\
\hline $\begin{array}{l}\text { Fatos } \\
\text { relevantes }\end{array}$ & $\begin{array}{l}\text { - Abertura de novos e } \\
\text { reaparelhamento de Estaleiros } \\
\text { - 1970: Brasil } 2^{\circ} \text { Maior Parque } \\
\text { Industrial Naval do Mundo }\end{array}$ & $\begin{array}{l}\text { - Crise econômica da década } \\
\text { de } 1980 \text { inviabilizou as } \\
\text { encomendas (em larga } \\
\text { escala) dos maiores } \\
\text { armadores estatais (Petrobrás } \\
\text { e Vale do Rio Doce) } \\
\text { - Sobrecarga do sistema de } \\
\text { financiamento }\end{array}$ & $\begin{array}{l}\text { - Novo quadro devido à } \\
\text { exploração de petróleo } \\
\text { offshore } \\
\text { - Aumento de contratações de } \\
\text { serviços de embarcações de } \\
\text { apoio marítimo }\end{array}$ & $\begin{array}{l}\text { - Sete Brasil com problemas } \\
\text { financeiros } \\
\text { - Diminuição de demandas } \\
\text { pela Transpetro/Petrobras }\end{array}$ \\
\hline Políticas & $\begin{array}{l}\text { - Década de 1950: Lei do } \\
\text { Fundo de Marinha Mercante } \\
\text { (FMM); Adicional de Frete } \\
\text { para Renovação da Marinha } \\
\text { Mercante (AFRMM); Grupo } \\
\text { Executivo da Indústria de } \\
\text { Construção Naval (Geicon); } \\
\text { Comissão de Marinha } \\
\text { Mercante (CMM) } \\
\text { - Década de 1960: o Plano de } \\
\text { Emergência de Construção } \\
\text { Naval (PECN, 1969) e } \\
\text { Programas de Construção } \\
\text { Naval (I PCN, 1971; II PCN, } \\
\text { 1975) }\end{array}$ & $\begin{array}{l}\text { - Década de 1990: a abertura } \\
\text { do mercado de navegação/ } \\
\text { concorrência internaciona }\end{array}$ & $\begin{array}{l}\text { - 1997: Lei do Petróleo } \\
\text { - 1999: Programa de Apoio } \\
\text { Marítimo - Prorefam } \\
\text { - 2000: Programa Navega } \\
\text { Brasil } \\
\text { - 2003: Programa de } \\
\text { Mobilização da Indústria } \\
\text { Nacional de Petróleo e } \\
\text { Gás Natural - Prominp } \\
\text { - Programa de índices de } \\
\text { nacionalização pela ANP } \\
\text { - 2004: Programa de } \\
\text { Modernização e Expansão da } \\
\text { Frota - Promef } \\
\text { - 2010: Programa de Empresa } \\
\text { Brasileira de Navegação } \\
\text { - EBN }\end{array}$ & \\
\hline $\begin{array}{l}\text { Estrutura } \\
\text { da indústria }\end{array}$ & $\begin{array}{l}\text { - Número reduzido de } \\
\text { grandes empresas nacionais e } \\
\text { estrangeiras }\end{array}$ & $\begin{array}{l}\text { - Número reduzido de } \\
\text { grandes empresas nacionais e } \\
\text { estrangeiras }\end{array}$ & $\begin{array}{l}\text { - Internacionalização } \\
\text { e entrada de grandes } \\
\text { construtores navais como } \\
\text { sócios nos estaleiros } \\
\text { brasileiros }\end{array}$ & - Diminuição de investimentos \\
\hline Trabalhadore & $\begin{array}{l}-1960: 1.430 \\
-1979: 39.155\end{array}$ & $\begin{array}{l}\text { - 1998: } 1.880 \text { (menor índice } \\
\text { desde a década de 1960) }\end{array}$ & $\begin{array}{l}\text { - 2014: } 82.472 \text { (maior índice } \\
\text { da história da ICNB) }\end{array}$ & - 2015: 57.048 \\
\hline
\end{tabular}

Fonte: Elaboração própria, a partir de Suzigan (2000); Lima e Velasco (1998); Pasin (2002); Borges e Silva (1993); MDICE (2002); BNDES (1997); Furtado et al. (2003), Furtado (2002); Jesus (2013). 
Esse cenário só mudou, a partir de fins dos anos 1990, especialmente devido a um conjunto de políticas de grande relevância que fomentou a retomada da indústria naval brasileira, especialmente a Lei do Petróleo (lei 9.478/1997); as mudanças nas políticas de compras da Petrobras; o Programa de Apoio Marítimo - Prorefam; o Programa Navega Brasil; o Programa de Mobilização da Indústria Nacional de Petróleo e Gás Natural - Prominp; o Programa de Modernização e Expansão da Frota - Promef; e o Programa de Empresa Brasileira de Navegação - EBN.

Com isso, o governo brasileiro, visando estimular o setor, atuou, em conjunto com a Petrobras/Transpetro, com medidas e políticas diretas para indústria. Na prática, essas empresas efetuaram grandes encomendas aos estaleiros nacionais, enquanto a união atuou com exigências de percentual mínimo de conteúdo local nas atividades de exploração e produção, com incentivos fiscais, além da concessão de crédito aos agentes financeiros do Fundo de Marinha Mercante (FMM) ${ }^{11}$ (Jesus, 2013).

Essa retomada da indústria naval trouxe um novo cenário, com crescentes resultados positivos dos principais indicadores do setor, como produção e emprego, reabertura de estaleiros e implantação de novos pelo território nacional. Definimos esse período de grande reativação e expansão das atividades de retomada, entre os anos 1997 a 2014, como de retomada das atividades dessa indústria no País. Com isso, em 2014 chegamos ao maior volume de emprego da construção naval brasileira, aproximadamente 82,5 mil trabalhadores (Gráfico 1).

Gráfico 1 - Volume total de emprego na Indústria Naval - Brasil, 1960/2016

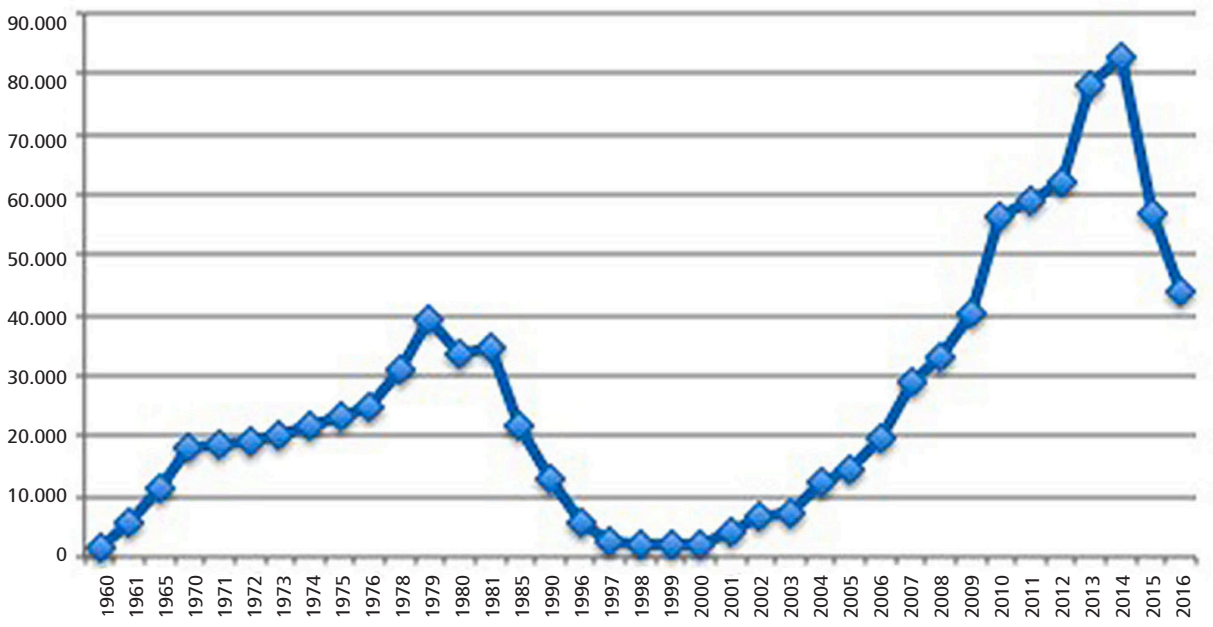

*Valores no final de cada ano, para o ano de 2016 até junho.

Fonte: Elaboração própria a partir de Sinaval (Cenários de vários anos). 
Entretanto, a partir do ano de 2015, observamos uma nova fase para a indústria naval brasileira, com forte inflexão das inversões no setor, devido a problemas envolvendo a Transpetro, a Petrobras e a Sete Brasil. De acordo com dados do Sinaval (2016), o número de trabalhadores caiu para 57 mil aproximadamente, ou seja, 25,4\% a menos que 0 ano anterior. Dados preliminares mostram tendência de diminuição em todos os indicadores do setor para 2016.

Após essa análise da evolução e de características do mercado de trabalho naval no Brasil, passaremos ao estudo do caso da indústria naval na Região Metropolitana do Rio de Janeiro, com descrição e análise dessa região e a identificação das principais plantas produtivas navais além dos projetos de desconcentração regional da indústria.

\section{A indústria naval na Região Metroplitana do Rio de Janeiro}

O Rio de Janeiro é um dos menores estados do Brasil, considerando-se suas dimensões físicas. Seus 92 municípios estão distribuídos em aproximadamente 44 mil km², correspondente a $0,5 \%$ do território nacional. Para fins político-administrativos, o Governo estadual divide o território fluminense em oito regiões de governo, marcadas por profundas diferenças em relação às estruturas urbanas e produtiva, bem como à distribuição populacional ${ }^{12}$ (Silva, 2009).
A Região Metropolitana do Rio de Janeiro será objeto de estudo neste artigo, mais precisamente três de seus dezenoves municípios: Rio de Janeiro, Niterói e São Gonçalo. Juntos, os três correspondem a $49 \%$ da população estadual, ainda que a tão somente $4 \%$ do território. Por outro lado, em 2013, representavam $47 \%$ do Valor Adicionado Bruto estadual $^{13}$ (Tabela 1).

Algumas questões de fundo devem ser explicitadas antes de nos determos na análise mais específica sobre a indústria naval. Primeiramente, deve-se registrar que o estado do Rio de Janeiro experimentou uma certa recuperação econômica entre fins dos anos 1990 e 2013. Essa trajetória se diferenciava do padrão de perdas de participação relativa na economia nacional, observado desde a segunda década do século XX. Ainda que não se possa falar em total ruptura do que se convencionou chamar de "esvaziamento econômico" do Rio de Janeiro, há grande segurança em apontar que o momento vivido representava uma dinâmica expansiva diferenciada, afora as perspectivas que rapidamente se avolumavam.

Em princípio, esse movimento se fez por força do movimento expansivo vivenciado pela produção de petróleo na Bacia de Campos, na Região Norte fluminense. Mas, logo, observou-se um tímido movimento de espraiamento da dinâmica de extração de petróleo para outros setores correlatos, caso da indústria naval e petroquímica. De meados da década de 2000 em diante se verificou também a ampliação do investimento em logística urbana e produtiva, com a tentativa de expansão de outros setores pelo território estadual e atendimento de uma 
Tabela 1 - Rio de Janeiro, Niterói e São Gonçalo dados selecionados comparação ERJ

\begin{tabular}{l|c|c|c|c}
\hline Municípios & População 2010 & $\begin{array}{c}\text { Área da Unidade } \\
\text { Territorial 2015 } \\
\left(\mathbf{K m}^{2}\right)\end{array}$ & $\begin{array}{c}\text { Densidade } \\
\text { Demográfica 2010 } \\
\left(\text { Hab/Km²) }^{2}\right.\end{array}$ & $\begin{array}{c}\text { Valor Adicionado } \\
\text { Bruto 2010 }\end{array}$ \\
\hline Niterói & 487.562 & 133 & $3.640,8$ & 17.696 .646 \\
Rio de Janeiro & 6.320 .446 & 1.200 & $5.265,8$ & 219.879 .081 \\
São Gonçalo & 999.728 & 248 & $4.035,9$ & 13.031 .872 \\
Total 3 cidades & 7.807 .736 & 1.581 & $12.942,5$ & 250.607 .599 \\
\% em ERJ & 49 & 4 & - & 47 \\
Total ERJ & 15.989 .929 & $43.781,70$ & 365,2 & 533.080 .722 \\
\hline
\end{tabular}

Fonte: IBGE (2016).

agenda poderosa em exigências para os recebimentos dos megaeventos esportivos. Assim, o estado do Rio de Janeiro e, particularmente, sua região metropolitana se inseriram na dinâmica expansiva da economia nacional, através da maior presença e do ativismo estatal na coordenação do investimento, via parcerias público-privadas ou como "fomentador" de demandas setoriais específicas, caso este da indústria naval.

Analisando o mapa da indústria naval brasileira, fica patente a importância do estado do Rio de Janeiro. 0 estado ainda concentra grande parte das unidades e do emprego gerado pelo setor, realidade esta devida ao fato de sê-lo o berço dessa indústria em território nacional e detentor dos maiores parques navais. ${ }^{14}$ Regionalmente, a Região Metropolitana e a cidade de Angra dos Reis (na Costa Verde) são as espinhas dorsais da produção naval estadual (Quadros 2 e 3).

Entretanto, dos trinta e dois estaleiros mais importantes (de grande e médio porte) sediados no Brasil, grande parte está no estado do Rio de Janeiro (Quadros 2 e 3 e Figura 1). Entre estes, destacam-se os estaleiros Brasfels (Angra dos Reis), Eisa (Ilha do Governador na cidade do Rio de Janeiro) e Mauá (com quatro plantas produtivas: a) Unidade Ponta d'Areia - Niterói b) Ilha do Caju - Niterói/RJ; c) Ilha da Conceição - Rio de Janeiro; e d) São Gonçalo/RJ). 
Quadro 2 - Estaleiros de grande porte no Brasil por estado - 2015

\begin{tabular}{|l|c|l|}
\hline Estaleiros de grande porte & Estado & \multicolumn{1}{|c|}{ Carteira } \\
\hline Estaleiro Atlântico Sul & PE & Navios petroleiros de grande porte, sondas de perfuração e plataformas de produção \\
\hline Brasfels & RJ & Plataformas de produção e sondas de perfuração \\
\hline Estaleiros Rio Grande & RS & Plataformas de produção e sondas de perfuração \\
\hline Eisa & RJ & Navios graneleiros, porta-contêineres, navios de apoio marítimo e navios-patrulha \\
\hline Estaleiro Mauá & RJ & Navios petroleiros e de produtos \\
\hline Vard Promar & PE & Navios gaseiros \\
\hline QGI & RS & Integração de módulos a plataformas de petróleo \\
\hline
\end{tabular}

Fonte: Sinaval (2015).

\section{Quadro 3 - Estaleiros de médio porte no Brasil por estado - 2015}

\begin{tabular}{|c|c|c|}
\hline Estaleiros de médio porte & Estado & Carteira \\
\hline Aliança Indústria Naval & RJ & Navios de apoio marítimo \\
\hline Vard Niterói & RJ & Navios de apoio marítimo \\
\hline Wilson, Sons & SP & Navios de apoio marítimo e rebocadores portuários \\
\hline Estaleiro São Miguel & RJ & Navios de apoio marítimo \\
\hline Arpoador Engenharia & RJ e SP & Navios de apoio marítimo \\
\hline Detroit Brasil & SC & Navios de apoio marítimo e rebocadores portuários \\
\hline DSN Equipemar & RJ & Navios de apoio marítimo \\
\hline Enaval Engenharia Naval & RJ & Navios de apoio marítimo e módulos para plataformas \\
\hline Estaleiro Navship & SC & Navios de apoio marítimo \\
\hline Estaleiro Oceana & SC & Navios de apoio marítimo \\
\hline ETP Engenharia & RJ & Navios de apoio marítimo \\
\hline Intecnial & $\mathrm{RS} / \mathrm{SC}$ & Navios de apoio marítimo, empurradores e barcaças fluviais \\
\hline Keppel Singmarine & SC & Navios de apoio marítimo \\
\hline Naproservice & RJ & Manutenção e reparos navais e offshore \\
\hline Rio Nave & RJ & Navios de produtos e gaseiros \\
\hline Sermetal & RJ & Reparos e manutenção \\
\hline UTC Engenharia & RJ & Integração de módulos para plataformas \\
\hline Inace & CE & Navios-patrulha e navios de apoio marítimo \\
\hline Easa & PA & Barcaças e empurradores fluviais \\
\hline Estaleiro Bibi & AM & Barcaças e empurradores fluviais \\
\hline Rio Maguari & PA & Barcaças e empurradores fluviais \\
\hline Rio Tietê & SP & Barcaças e empurradores fluviais \\
\hline Estaleiro Navship & SC & Navios de apoio marítimo \\
\hline Estaleiro Oceana & SC & Navios de apoio marítimo \\
\hline
\end{tabular}

Fonte: Sinaval (2015). 
Até a década de 1990, a grande maioria dos estaleiros do País se localizava no estado do Rio de Janeiro. No período de retomada da indústria, especialmente observado a partir de 2003, as políticas foram planejadas com o intuito de desconcentrar a indústria naval pelo território do País, para além, portanto, do estado do Rio de janeiro, com a criação de novos polos navais, estruturada a partir do conceito de formação de polos regionais da construção naval.
A caracterização desses polos navais se basearia na existência de estaleiros e estruturas de serviços e fornecedores operando de forma contínua. A implantação dos polos regionais teve como objetivo descentralizar a indústria, a partir de terrenos com acesso ao mar, em condições de receber estaleiros que demandassem grandes áreas de armazenagem, oficinas, diques secos e cais de acabamento.

Assim, os investimentos foram pensados para os seguintes polos: a) Polos Navais do

Figura 1 - Mapa do estado do Rio de Janeiro com principais estaleiros por cidade - 2014

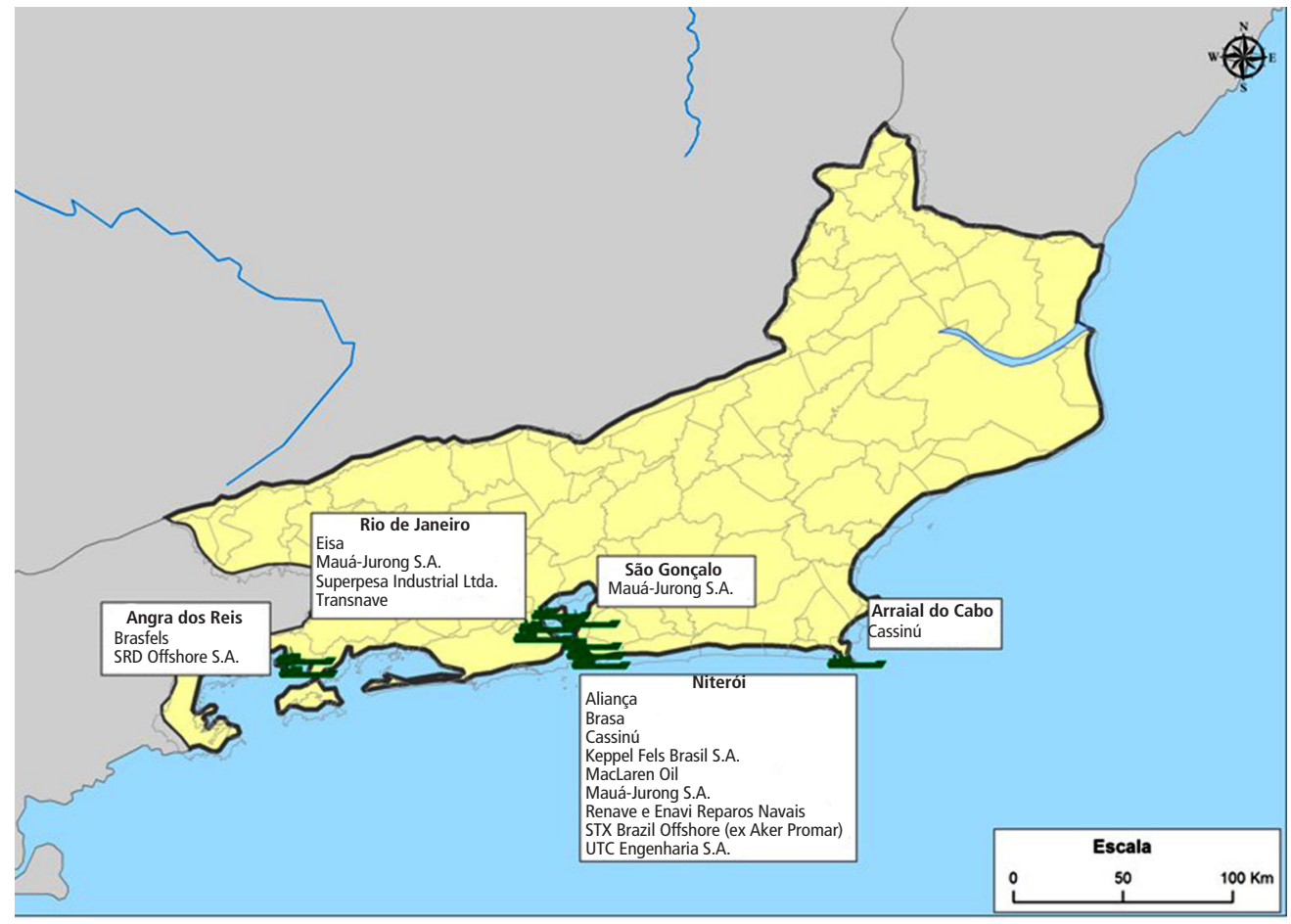

Fonte: Elaboração própria, 2016. 
Pará e Amazonas; b) Polo Naval de Pernambuco; c) Polo Naval da Bahia; d) Polo Naval do Espírito Santo; e) Polo Naval do Rio de Janeiro; e) Polo Naval de Santa Catarina e f) Polo Naval do Rio Grande do Sul.

Contudo, o Rio de Janeiro continuou sendo o principal polo naval do País, pois tinha a vantagem de contar com um conjunto de grandes estaleiros, mas também estaleiros de médio porte, tais como o Rio Nave (Rio de Janeiro), Aliança, Vard, Brasa, Mac Laren Oil (Niterói) e Cassinú e São Miguel (São Gonçalo). Justamente essa variedade permitiu que o Rio de Janeiro tivesse e mantivesse a mais diversificada capacidade de construção naval do País (Sinaval, 2016).

Ademais, o Rio de Janeiro era, também, o único estado que de maneira mais substancial possuía uma vantagem comparativa em relação aos concorrentes nacionais: dado que grande parte de seus estaleiros data dos anos 1960, eles apresentaram grande capacidade de reestruturação de processos produtivos, em muito por conta da já estabelecida cultura do trabalhador naval. Vale lembrar que o Rio de Janeiro, quando do início dos trabalhos do Estaleiro do Atlântico Sul (em Pernambuco), enviou trabalhadores experientes na construção naval, tendo em vista as dificuldades de o estaleiro nordestino em conseguir mão de obra qualificada, cuja qualificação tem forte conteúdo learning by doing.

Quando do planejamento dessas políticas de descentralização da indústria naval, observaram-se fortes críticas por parte dos estaleiros fluminenses aos investimentos em outros estados. Talvez a de maior projeção tenha sido a que destaca que o Rio de Janeiro possuía as principais plantas, a especialização e a cultura naval em seus trabalhadores, porém, por falta de investimentos, seus estaleiros estariam sofrendo com defasagem tecnológica. Em adição, como no Rio de Janeiro já existia uma aglomeração setorial, seria um erro a descentralização dos investimentos, dado que eles não usufruiriam de economias de aglomeração, algo central para o setor com características técnicas, operacionais e de demanda tão particulares.

Apesar desses argumentos, foram construídos novos polos de construção em Pernambuco e Rio Grande do Sul. Em Pernambuco, na área industrial do Porto de Suape, foi instalado o Estaleiro Atlântico Sul - EAS, e a implantação do Promar-Vard Suap. Já o polo do Rio de Grande do Sul se expandiu em duas regiões: com os estaleiros Rio Grande e Quip em Rio Grande; e com o Estaleiro Brasil (EBR), em São José do Norte, e com as unidades industriais localizadas em Charqueadas.

Por sua vez, o polo naval de Santa Catarina, situado em Navegantes, foi ampliado com a expansão dos estaleiros Detroit e Keppel Sigmarine e a implantação do Navship. Na cidade de Itajaí, o Construção Naval Itajaí daria continuidade à tradição de construção de navios gaseiros.

Além desses, havia outros dois novos polos navais, um no estado do Espírito Santo, com o Estaleiro Jurong Aracruz (EJA), e outro no estado da Bahia, com o Estaleiro Enseada do Paraguaçu (EEP), ambos pensados para a construção de navios-sonda (Sinaval, 2016). Contudo, os projetos foram paralisados com as últimas notícias do setor no Brasil.

Por fim, no estado do Amazonas, havia a expectativa de um projeto de implantação de mais um polo naval no País, projeto ainda não concluído. A nova zona industrial abrigaria sete 
estaleiros de médio porte, com investimentos locais e internacionais. Essa diversificação aponta para uma sustentabilidade da construção naval que é capaz de atender a demandas locais e do setor offshore (ibid.).

Todo esse contexto, pensando em momento de crescimento da indústria no País, sofreu uma forte mudança a partir de 2014. No próximo tópico, tentaremos analisar os desafios contemporâneos do mercado de trabalho da indústria no País e em especial na Região Metropolitana no Rio de Janeiro no momento atual, especialmente como base os dados da Rais/MTE.

\section{Desafios contemporâneos do mercado de trabalho na indústria naval na região metropolitana fluminense}

Não obstante todos os grandes investimentos pelo País, o estado do Rio de Janeiro permaneceu concentrando a maior parte dos estaleiros e do volume de emprego do setor. E especialmente sua região metropolitana permaneceu com forte centralidade para o mercado de trabalho e para a produção setorial nacional. Entre 2006 e 2014, o montante de empregos diretos gerados pela construção naval brasileira saltou de pouco mais de 25 mil unidades para a casa das 71 mil unidades. Ainda que tenha crescimento percentual abaixo da média nacional, o estado se manteve em destaque, respondendo por cerca da metade dos empregos gerados no setor. A RMRJ, por sua vez, respondia por aproximadamente 1 em cada 3 empregos gerados nacionalmente e a 2 em cada 3 dentro do estado do Rio.

Todavia, as taxas de participação do estado como um todo e de sua região metropolitana caíram no conjunto nacional, por ocasião do processo de desconcentração setorial em direção a outras partes do território brasileiro. Destaca-se que entre 2006 e 2014 a participação fluminense no volume de emprego da indústria naval brasileira caiu de $71 \%$ para $50 \%$, segundo dados da Rais (Tabela 2 e Gráfico 2).

Essa perda de participação também se observou em nível metropolitano. No mesmo período, a participação da RMRJ no volume de emprego naval nacional foi reduzida de $44 \%$ para 33,7\%. No entanto, é muito importante ressaltar que a queda de participação não se deu por perdas reais do volume de emprego, mas pelo crescimento mais acelerado do emprego, em termos percentuais, nos novos espaços da produção naval nacional. Nota-se que, entre 2006 e 2014, o incremento de empregos totais na RMRJ foi de pouco mais de $13 \mathrm{mil}$ unidades $(267,2 \%)$, ao passo que, em nível nacional (excluindo-se a RMRJ), o incremento foi da ordem de 33,3 mil ou 336,9 por cento.

Entretanto, para 2015, os dados preliminares da Rais mostram um total de 55,2 mil trabalhadores navais aproximadamente, número muito menor que 0 ano anterior,com 71,6 mil, uma redução de 16,4 mil postos de empregos ou de, aproximadamente, $23 \%$. Isso mostra um claro indicativo de desaceleração das atividades e desaquecimento do mercado de trabalho setorial, em razão de fatores que veremos a seguir.

Analisando a distribuição dos trabalhadores navais do Brasil nas faixas de remuneração salarial média, para os anos de 2006 e 
Tabela 2 - Evolução do volume de emprego da indústria de construção naval no Brasil - 2006-2014

\begin{tabular}{l|r|r|r|r|r|r|r|r|r}
\hline \multicolumn{1}{c|}{ Anos } & \multicolumn{1}{c|}{2006} & \multicolumn{1}{c|}{2007} & \multicolumn{1}{c|}{2008} & \multicolumn{1}{c|}{2009} & \multicolumn{1}{c|}{2010} & 2011 & 2012 & \multicolumn{1}{c}{2013} & 2014 \\
\hline Brasil & 25.138 & 25.739 & 33.112 & 35.431 & 41.554 & 46.441 & 59.260 & 68.042 & 71.554 \\
Estado RJ & 18.621 & 18.243 & 22.685 & 22.769 & 24.809 & 25.237 & 31.130 & 32.476 & 35.901 \\
Estado RJ & 74,1 & 70,9 & 68,5 & 64,3 & 59,7 & 54,3 & 52,5 & 47,7 & 50,2 \\
Região Metrop. RJ & 11.066 & 10.500 & 14.960 & 14.731 & 15.287 & 16.356 & 20.482 & 22.167 & 24.148 \\
Região Metrop. RJ & 44,0 & 40,8 & 45,2 & 41,6 & 36,8 & 35,2 & 34,6 & 32,6 & 33,7 \\
\hline
\end{tabular}

Fonte: Elaboração própria a partir de Rais (2006-2014).

\section{Gráfico 2 - Participação do ERJ e Região Metropolitana RJ no volume de emprego naval - Brasil 2006-2014}

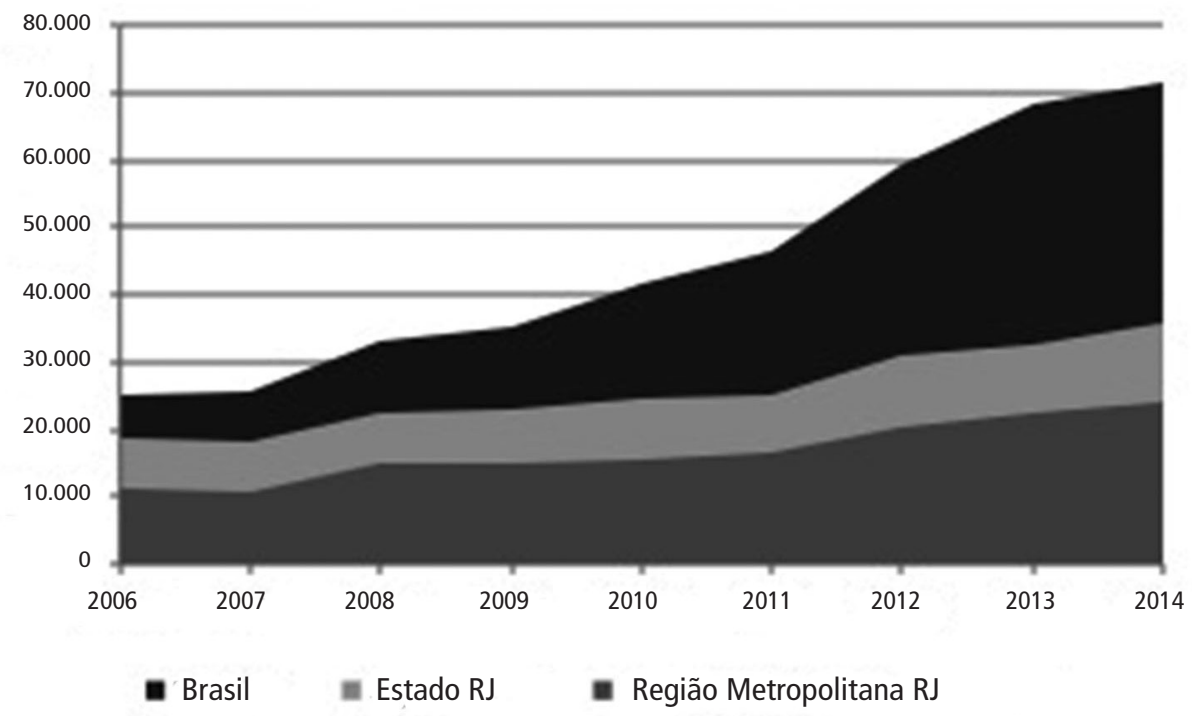

Fonte: Elaboração própria a partir de Rais (2006-2014). 
Tabela 3 - Distribuição dos trabalhadores da indústria de construção naval por faixa salarial em salários mínimos, Brasil, 2006-2015 (em \%)

\begin{tabular}{l|r|r|r|r|r|r|r|r|r|c}
\hline \multicolumn{1}{c|}{$\begin{array}{c}\text { Faixa Remuneração } \\
\text { Média (SM) }\end{array}$} & $\mathbf{2 0 0 6}$ & $\mathbf{2 0 0 7}$ & $\mathbf{2 0 0 8}$ & $\mathbf{2 0 0 9}$ & $\mathbf{2 0 1 0}$ & $\mathbf{2 0 1 1}$ & $\mathbf{2 0 1 2}$ & $\mathbf{2 0 1 3}$ & $\mathbf{2 0 1 4}$ & $\mathbf{2 0 1 5}$ \\
\hline Até 2,00 & 13,8 & 17 & 18,1 & 21,4 & 19,6 & 17,9 & 19,1 & 17,4 & 15,8 & 17,0 \\
2,01 a 3,00 & 17,2 & 18,5 & 18,2 & 19,0 & 21,6 & 20,0 & 22,0 & 23,2 & 21,6 & 23,5 \\
3,01 a 4,00 & 15,6 & 17,4 & 17,8 & 17,8 & 18,4 & 19,4 & 21,5 & 20,3 & 20,6 & 22,3 \\
4,01 a 5,00 & 14,4 & 14,2 & 16,6 & 15,0 & 14,5 & 14,5 & 13,6 & 14,8 & 16,4 & 12,6 \\
5,01 a 7,00 & 21,8 & 16,9 & 14,5 & 12,2 & 11,3 & 12,1 & 8,7 & 9,3 & 10,4 & 8,7 \\
7,01 a 10,00 & 7,8 & 6,2 & 5,5 & 4,7 & 4,5 & 4,9 & 4,4 & 4,8 & 4,9 & 4,6 \\
10,01 a 15,00 & 3,6 & 3,2 & 3,2 & 2,9 & 3,0 & 3,2 & 3,3 & 3,5 & 3,4 & 3,0 \\
Mais de 15,01 & 2,7 & 1,5 & 2,6 & 2,6 & 2,7 & 3,5 & 3,8 & 3,6 & 3,9 & 3,9 \\
Sem Classificação & 2,9 & 4,1 & 3,6 & 4,3 & 4,4 & 4,4 & 3,4 & 3,2 & 2,9 & 5,3 \\
\hline Total & 100,0 & 100,0 & 100,0 & 100,0 & 100,0 & 100,0 & 100,0 & 100,0 & 100,0 & 100,0 \\
\hline
\end{tabular}

Fonte: Elaboração própria, a partir de Rais/MTE (2006-2015).

2015, observamos que para o grupo correspondente aos trabalhadores que ganhavam cinco salários mínimos ou menos, houve forte ampliação no período; somadas, passaram de $61 \%$ para $75,4 \%$, enquanto todos os empregados com mais de cinco salários sofreram redução; somadas, no ano de 2006, correspondiam a quase $35,9 \%$ e, em 2015, a apenas 20,2\% do total (Tabela 3).

Em 2006, o maior percentual de trabaIhadores navais do total do País, 21,8\%, que se encontrava na faixa de recebimentos entre 5,01 e 7 salários mínimos, caiu para $8,7 \%$ do total. Já, em 2015, a situação mudou: os trabalhadores com maior percentual foram os correspondentes aos empregados que ganhavam de dois a três salários mínimos, 23,5\% do total.
No caso da Região Metropolitana do Rio de Janeiro - Tabela 4 -, o grupo correspondente aos trabalhadores que ganhavam até cinco salários mínimos teve ampliação no período, passando de $57,4 \%$ para 64,9 . Enquanto isso, todas as faixas referentes aos empregados que ganhavam mais de cinco salários sofreram redução. Em 2006, somadas, correspondiam a $39,6 \%$ e, em 2015, a apenas 23,3\% do total (Tabela 4). Ao compararmos com o total de trabalhadores do País, os trabalhadores da RMRJ encontravam-se distribuídos em faixas de salários maiores.

Em 2006, ainda para os trabalhadores navais da Região Metropolitana do Rio de Janeiro, o maior percentual de trabalhadores, $24,3 \%$, encontrava-se na faixa de recebimentos entre 5,01 e 7 salários mínimos, caindo 
para $11,5 \%$ do total. No ano de 2015 , a situação mudou, os trabalhadores com maior percentual foram os correspondentes aos empregados que ganhavam de dois a três salários mínimos, correspondendo a 24,9\%. Portanto, concluímos que ocorreu uma redução significativa dos rendimentos dos trabalhadores navais em salários mínimos no período. Contudo, vale destacar e é preciso considerar a forte valorização do salário mínimo no País, ocorrida no período, de maio de 1995 a janeiro de 2010, um aumento real acumulado de $71,8 \%$ (Dieese apud Jesus, 2013).

Os dados anteriores indicam um crescente aumento do desemprego e mesmo uma gradativa diminuição dos menores salários. A questão que se apresenta eé como ficará o emprego dos trabalhadores navais brasileiros nesse cenário de nova crise setorial?
Esse novo cenário de crise na indústria de construção naval se inicia no pós-ano 2014 e tem como cerne a crise pela qual vem passando a Petrobras, principal demandante dos serviços dos estaleiros brasileiros. Essa crise decorre tanto da queda nos preços internacionais do Petróleo, como da Operação Lava Jato, que atingiu diretamente a Trasnpetro e a Sete Brasil (empresa criada para intermediar a construção de sondas do pré-sal). ${ }^{15}$

Destaca-se que a Transpetro (subsidiária da Petrobras) diminuiu a demanda por encomendas aos estaleiros, e a Sete Brasil está com dificuldades financeiras em meio a um processo de recuperação judicial. Um possível agravamento na situação da Sete Brasil pode aprofundar mais ainda os problemas de desemprego, tendo em vista que essa empresa (criada em 2010) viabilizaria dois novos

Tabela 4 - Distribuição dos trabalhadores da indústria de construção naval por faixa salarial em salários mínimos, RMRJ, 2006-2015 (em \%)

\begin{tabular}{l|r|r|r|r|r|r|r|r|r|r}
\hline \multicolumn{1}{c|}{$\begin{array}{c}\text { Faixa Remuneração } \\
\text { Média (SM) }\end{array}$} & $\mathbf{2 0 0 6}$ & $\mathbf{2 0 0 7}$ & $\mathbf{2 0 0 8}$ & $\mathbf{2 0 0 9}$ & $\mathbf{2 0 1 0}$ & $\mathbf{2 0 1 1}$ & $\mathbf{2 0 1 2}$ & $\mathbf{2 0 1 3}$ & $\mathbf{2 0 1 4}$ & $\mathbf{2 0 1 5}$ \\
\hline Até 2,00 & 7,1 & 11,0 & 10,2 & 10,7 & 11,1 & 12,0 & 12,3 & 11,4 & 8,5 & 7,9 \\
2,01 a 3,00 & 16,1 & 16,9 & 18,9 & 18,7 & 19,2 & 18,2 & 20,1 & 22,3 & 19,6 & 16,2 \\
3,01 a 4,00 & 18,0 & 20,5 & 21,3 & 22,0 & 22,4 & 23,9 & 26,0 & 26,6 & 24,4 & 24,9 \\
4,01 a 5,00 & 16,2 & 15,4 & 18,1 & 17,9 & 16,9 & 17,0 & 14,0 & 16,3 & 21,5 & 15,9 \\
5,01 a 7,00 & 24,3 & 18,2 & 17,0 & 16,0 & 14,0 & 12,4 & 10,2 & 8,5 & 10,7 & 11,5 \\
7,01 a 10,00 & 7,7 & 6,5 & 5,3 & 4,5 & 4,6 & 4,1 & 4,5 & 4,2 & 4,7 & 5,2 \\
10,01 a 15,00 & 4,1 & 4,0 & 2,8 & 2,6 & 2,6 & 2,8 & 2,8 & 2,4 & 2,6 & 3,3 \\
Mais de 15,01 & 3,5 & 3,3 & 2,4 & 2,6 & 3,1 & 3,0 & 4,1 & 2,9 & 3,0 & 3,3 \\
Sem Classificação & 3,0 & 4,3 & 3,8 & 5,0 & 6,1 & 6,6 & 4,9 & 5,2 & 5,0 & 11,9 \\
\hline Total & 100,0 & 100,0 & 100,0 & 100,0 & 100,0 & 100,0 & 100,0 & 100,0 & 100,0 & 100,0 \\
\hline
\end{tabular}

Fonte: Elaboração própria a partir de Rais/MTE (2006-2015). 
estaleiros: Jurong Aracruz no ES e Enseada do Paraguaçu na BA, além de garantir a ampliação dos estaleiros EAS, OSX, Brasfels e ERG2 (Schutte, 2012).

De grande importância na indústria naval brasileira, a Região Metropolitana do Rio de Janeiro, desde 2015, tem refletido a forte redução das atividades da indústria de óleo e de gás do País com cerca de dez mil trabalhadores demitidos. E o número tende a aumentar, já que estaleiros, como Vard Promar e Aliança, estão sob risco de encerramento de suas atividades para os próximos meses, enquanto outros, como 0 Brasa e o Inhaúma (Enseada Indústria Naval), têm seu futuro indefinido, tendo em vista a falta de novas encomendas. Tudo isso, após o fechamento do Eisa Petro 1, em Niterói, que demitiu duas mil pessoas no fim de 2015, além do Eisa, na Ilha do Governador, que demitiu outros três mil (Rosa e Ordoñez, 2016).

0 orçamento do Rio de Janeiro teve impactos negativos com a queda da arrecadação dos royalties do petróleo, além da redução do recolhimento de Imposto sobre Circulação de Mercadorias e Serviços (ICMS) do setor naval. Segundo a Secretaria de Fazenda do Estado do Rio, o tributo gerado pelo setor caiu de $R \$ 8,5$ milhões, nos primeiros quatro meses do ano passado, para $\mathrm{R} \$ 4,7$ milhões no mesmo período deste ano, uma queda de 44,2\%. Em 2015, o recuo foi de quase $20 \%$, chegando a $\mathrm{R} \$ 17,6$ milhões (ibid.).

Em maio de 2016, o presidente do Vard Promar destacou que, com esse cenário, não haveria contrato novo em 2015 e 2016, depois que entregarem uma embarcação, que já estava sendo finalizada, pois iria fechar o estaleiro em Niterói no meio do ano. Dos 5 mil operários que circulavam pelas áreas do estaleiro Brasa no pico das obras em 2014, restavam menos de 1,2 mil. No prédio da área administrativa de três andares, um está tomado por dezenas de móveis novos sem utilidade, e o pátio, que antes fervilhava de trabalhadores, agora está quase vazio. ${ }^{16}$

A gerente de Petróleo, Gás e Naval da Firjan, Karine Fragoso, afirmou estimar que os estaleiros do Rio operam hoje com apenas 50\% de sua capacidade. Por outro lado, Marco Capute, atual secretário de Desenvolvimento do Rio, avaliou que tudo é ancorado na Petrobras, destacando que foram quase dez mil demissões e forte queda na arrecadação de ICMS. Além da falta de projetos, enfatizou ainda que muitas encomendas da Petrobras foram transferidas para a China. ${ }^{17}$

Com essa situação sendo desenhada na história naval brasileira, já se observam reflexos negativos, especialmente nos estaleiros da Região Metropolitana do Rio de Janeiro, com o fechamento do Estaleiro Eisa-Petro Um (antigo Mauá), em Niterói em julho de 2015, e do Eisa, na Ilha do Governador, na cidade do Rio de Janeiro, em dezembro de 2015. A situação pelo País não é diferente, especialmente difícil para os novos estaleiros, no caso, por exemplo, do Enseada do Paraguaçu, na Bahia, que já possuía quase sete mil trabalhadores e que, em julho de 2016, tem pouco mais de trezentos (ibid., 2016).

Com tudo isso, a indústria naval brasileira iniciou o que pode ser considerada uma nova crise na sua história. Apesar de recentes, os indicadores do setor já mostram uma forte retração, especialmente do volume de emprego naval no País. Enquanto, no ano de 2014, eram mais de 82 mil trabalhadores, em junho de 2016, eram apenas 43,7 mil. 
Com esse novo cenário, ressurge um problema para esses trabalhadores de cultura naval. Além de ficarem desempregados, ainda lidarão com a questão de ter uma qualificação extremamente específica e muito difícil de engradamento dentro de outros ramos da indústria metalurgia. A questão da formação do trabalhador na indústria naval é em grande medida obtida através de prática no local de trabalho (learning by doing). A formação na profissão através da prática real continua a ser o último modo de transmissão de conhecimentos e competências, especialmente nos casos dos operários-mestres (ou encarregados) responsáveis por parte da produção.

Concluindo, vale lembrar que, no período de retomada setorial (1997-2014), observou-se a revalorização dessa cultura. 0 Brasil, mas especialmente no estado do Rio de Janeiro, por ocasião de seu histórico nessa indústria, possuía uma mão de obra muito especializada e formada no chão de fábrica. Um exemplo claro vem dos trabalhadores de Angra dos Reis que, com a reabertura do estaleiro Brasfels, viram os encarregados e trabalhadores mais experientes, antes demitidos quando do fechamento do estaleiro Verolme, na década de 1990, serem readmitidos e reassumirem suas funções. ${ }^{18}$

\section{Considerações finais}

A Região Metropolitana do Rio de Janeiro, assim como o estado, é historicamente a região mais importante para o setor de construção naval brasileiro. A representatividade em termos de plantas produtivas, muitas desde da década de 1960, e com isso uma cultura naval na produção e no emprego fazem com que essa importância se sustente nos dias de hoje. Com a redução dos indicadores da indústria naval, a RMRJ, assim como o País, está sendo impactada consequentemente com o fechamento de estaleiros e as constantes/crescentes demissões.

A indústria naval em todo o mundo possui como característica marcante forte apoio governamental para sua existência e permanência, portanto esse novo cenário nacional com a descontinuidade de investimentos e a falta de apoio do governo federal (pós-2014) leva a uma nova fase de descontinuidade do dinamismo da indústria naval nacional. Como principal resultado observado no mercado de trabalho naval, destacamos, neste artigo, a perda de postos de trabalho: só de 2014 para 2015 foram 16,4 postos a menos. $E$ as projeções são de continuidade crescente dessa redução, além da perda da participação da Região Metropolitana do Rio de Janeiro no total dos trabalhadores navais do Brasil nos últimos anos.

Vale destacar que os novos acontecimentos descontinuam uma trajetória de fortes inversões e crescimento na indústria naval no País com importantes políticas que deram suporte a recuperação dessa indústria desde fins do século XX. Atualmente, o fechamento dos estaleiros ou mesmo a diminuição de suas atividades e o crescente desemprego, assentados em uma perspectiva de menos encomendas e financiamento por parte da Transpetro/Petrobras, definem uma nova fase na indústria naval no País, a qual se configura em uma nova crise. Entendendo essa nova fase, iniciada a partir do ano de 2014, como um novo ciclo na indústria naval brasileira, destacamos o desemprego como um dos principais resultados imediatos percebidos na descontinuidade dos indicadores do 
setor. Entendemos que, depois de mais de uma década de promessas, os trabalhadores navais da Região Metropolitana do Rio de Janeiro, assim como do País, fiquem "a ver navios" (e muitos desses produzidos fora da RMRJ ou mesmo fora do Brasil).

\section{Claudiana Guedes de Jesus}

Universidade Federal Rural do Rio de Janeiro, Instituto Multidisciplinar, Departamento de Administração e Turismo. Nova Iguaçu, RJ/Brasil.

claudiana.guedes@gmail.com

\section{Robson Dias da Silva}

Universidade Federal Rural do Rio de Janeiro, Instituto Multidisciplinar, Programa de Pós-Graduação em Desenvolvimento Territorial e Políticas Públicas. Nova Iguaçu, RJ/Brasil.

robsondsilva@gmail.com

\section{Notas}

(1) O Brasil, em 1979, ocupou o segundo lugar como maior parque naval mundial, em processamento de aço, atrás apenas do Japão.

(2) A saber, principais políticas, especialmente a Lei do Petróleo (lei 9.478/1997); as mudanças nas políticas de compras da Petrobras; o Programa de Apoio Marítimo - Prorefam; o Programa Navega Brasil; o Programa de Mobilização da Indústria Nacional de Petróleo e Gás Natural Prominp; o Programa de Modernização e Expansão da Frota - Promef; e o Programa de Empresa Brasileira de Navegação - EBN (Jesus, 2013)

(3) De acordo com a Classificação Nacional de Atividades Econômicas - CNAE, a indústria de construção naval faz parte da Indústria de Transformação, dentro do complexo metal-mecânico, no segmento de Fabricação de Outros Equipamentos de Transportes. Por isso, os trabalhadores da construção naval são chamados também de metalúrgicos.

(4) No tópico 3, utilizamos a Relação Anual de Informações Sociais base estatística do Ministério do Emprego e Trabalho - Rais/MTE, para tanto utilizamos os correspondentes abaixo: CNAE 2.0: Classe 30113 -- Construção de embarcações e estruturas flutuantes; Classe 30121 - Construção de embarcações para esporte e lazer; Classe 33171 - Manutenção e reparação de embarcações. 
(5) A velocidade de reação dos preços de um navio não é, entretanto, acompanhada pela redução imediata na oferta de novos navios. Isso porque o ciclo de produção de um navio é de aproximadamente 2 a 3 anos, considerado desde o momento da encomenda até a entrega. É evidente que o prazo de entrega depende do tipo de navio, que, de forma geral, no caso de transporte de carga, pode ser classificado como navios de transporte a granel (líquido ou sólido) e de carga em geral. (As embarcações podem ser classificadas conforme o uso. O Lloyd' Register Fairplay utiliza as seguintes categorias: Tanker (LNG, LPG, Químico, Petróleo, Outros), Bulk (Bulker, General Cargo, Other Dry), Contêiner (Contêiner, Veículos, Ro-ro), Passageiros (Ferry, Cruise, lates), Miscelânea (Offshore, Serviço, Pesca, Miscelânea)) (Negri et al., 2009, p. 6).

(6) Diques e carreiras; berços de acabamento; guindastes e área do parque industrial são os principais ativos que compõem a capacidade de produção de um estaleiro.

(7) A produção naval possui um tipo de produto - a embarcação - muito particular: trata-se, com efeito, de produtos não repetitivos. Isto significa que a organização do trabalho corresponde à de um processo de produção por unidade, em que a importância da estrutura profissional de ofício não desapareceu completamente. A previsibilidade técnica, e principalmente econômica, do trabalho e o controle das operações de produção são menores, a flexibilidade organizacional, a polivalência e a autonomia do nível de execução são mais amplas. As flutuações das encomendas tornam difícil a gestão racionalizada (Lima, 1981, p. 896).

(8) Principais exemplos de Entidades ou Sociedades classificadoras: Lloyd Register; American Bureau Shipping; Bureau Colombo; Bureau Veritas; Noësk Veritas; Germanischer Lloyd e Noble Danton (Sinaval, 2010).

(9) Armadores são empresas de transporte aquaviário que demandam embarcações novas e usadas, diretamente dos estaleiros ou através de trading companies e de outros brokers. Além disso, podem receber financiamento em condições privilegiadas de governos, especialmente eximbanks de países produtores de navios. Os agentes financeiros privados também contribuem com a definição de project finance para aquisição. Além distso, os armadores ainda contratam empresas classificadoras/certificadoras para inspecionar projetos, materiais e construção de seus navios (Coutinho, 2006). No caso do Brasil, no período de retomada, o principal armador é a Transpetro/Petrobras.

(10) A Sete Brasil foi criada em dezembro de 2010. Nesse caso, foi criada por sete investidores financeiros, entre os quais os três maiores fundos de pensão - Petros, Funcef e Previ, os bancos Bradesco, Santander, BTG Pactual e a própria Petrobras. A Petrobras fomentou a criação da Sete Brasil para passar segurança aos investidores quanto à construção das sondas de perfuração no Brasil. É esta empresa que fecha os contratos com os estaleiros (entre as quais a EAS) e, por sua vez, contratos de afretamento para a Petrobras. O menor tempo de uso das sondas é elemento determinante na redução de custos no pré-sal, pois $50 \%$ dos gastos se dão nessa fase do desenvolvimento. Para cada sonda será montada uma sociedade de propósito específico (SPE). Ela pretende garantir a produção de 30 sondas até 2020, das quais 28 são para a Petrobras e duas para o mercado spot. Para fornecer 28 sondas para o pré-sal, atualmente não tem dinheiro para continuar as obras e se tornou inadimplente com estaleiros e fornecedores (Sinaval, 2016).

(11) O Fundo de Marinha Mercante - FMM é um fundo de natureza contábil, destinado a prover recursos para o desenvolvimento da marinha mercante e da indústria de construção e reparação naval brasileira. Sua fonte básica de recursos é o Adicional ao Frete para a Renovação da Marinha Mercante (AFRMM), incidente sobre o frete cobrado pelo transporte aquaviário de carga de qualquer natureza descarregada em porto brasileiro, ou seja, sobre as atividades de cabotagem e importação de mercadorias (Dores, Lage e Processi, 2012). 
(12) Para fins políticos-administrativos, o Governo estadual divide o território fluminense em oito Regiões de Governo: Metropolitana, Noroeste Fluminense, Costa Verde, Norte Fluminense, Serrana, Centro-Sul Fluminense, baixadas Litorâneas, Médio Paraíba (Fundação Cide apud Silva, 2009).

(13) As cidades que compõem a região Metropolitana do Rio de Janeiro são Belford Roxo, Duque de Caxias, Guapimirim, Itaboraí, Japeri, Magé, Nilópolis, Niterói, Nova Iguaçu, Mesquita, Paracambi, Queimados, Rio de Janeiro, São Gonçalo, São João de Meriti, Seropédica e Tanguá (Fundação Cide apud Silva, 2009).

(14) O surgimento da indústria de construção naval de grande porte no Brasil ocorreu no século XIX, quando o empresário Barão de Mauá inaugurou o primeiro estaleiro do País, na localidade de Ponta da Areia, em Niterói (RJ) (Jesus, 2013).

(15) No dia 17 de março de 2014, a Polícia Federal Brasileira deflagrou a operação que viria a ser conhecida como Lava Jato, unificando quatro investigações que apuravam a prática de crimes financeiros e o desvio de recursos públicos. Inicialmente, foi identificada a atuação dos principais personagens do mercado clandestino de câmbio no Brasil no esquema criminoso investigado. Eram doleiros responsáveis pela movimentação financeira e lavagem de dinheiro de inúmeras pessoas físicas e jurídicas, o que acabava por envolver uma grande diversidade de outros crimes, como tráfico internacional de drogas, corrupção de agentes públicos, sonegação fiscal, evasão de divisas, extração, contrabando de pedras preciosas, desvios de recursos públicos, dentre outros. Para mais informações, ver site da Polícia Federal, disponível em: <http://www.pf.gov. br/imprensa/lava-jato>.

(16) Ademais, o presidente destacou ainda: "vou demitir 800 funcionários. Em 2015, eram 1.500 pessoas. Não vejo luz no fim do túnel" - disse Miro Arantes, presidente do Vard Promar, que busca investir em outras áreas na unidade de Pernambuco, hoje focada em embarcações de apoio (Rosa e Ordoñez, 2016). Setor naval afunda: sem novos projetos da Petrobras, estaleiros começam a fechar as portas e demitem em massa. Márcia Foletto / Agência $O$ Globo, 1/5/2016. Disponível em: http://oglobo.globo.com/economia/setor-naval-afunda19205832\#ixzz4lkDJsto4. Acesso em: 20 jul.

(17) O BrasFels, em Angra dos Reis, sente os efeitos da crise do setor. Dos nove mil trabalhadores em 2014, restam 4 mil. As obras das três sondas da Sete Brasil foram paralisadas, já que o estaleiro não recebe pagamentos da empresa desde 2014 e só opera com recursos próprios. "O estaleiro tem sido fortemente impactado pelo mercado em deterioração", disse a companhia. O BrasFels executa obras de duas plataformas para a Petrobras e um navio-sonda para Modec (Rosa e Ordoñez, 2016).

(18) Com a retomada, está acontecendo a procura desses trabalhadores experientes pelos novos estaleiros, como é o caso do Estaleiro do Atlântico Sul - EAS, em Pernambuco, que está fazendo propostas para os trabalhadores fluminenses. Portanto, nota-se que o atual período de retomada trouxe a evidência do conhecimento e da experiência do trabalhador naval como fator importante para a indústria (Jesus, 2013). 


\section{Referências}

BNDES (1997). Construção Naval no Brasil e no Mundo. Informe de Infraestrutura $n^{\circ} 14$. Área de Infraestrutura /Gerência de Estudos Setoriais 3.

BORGES, J. C. S. e CARLOS, R. L. (2003). Indústria da Construção Naval: a crise e recuperação. BNDES Conjuntura Setorial, julho, pp. 47-50.

COUTINHO, L.; SABBATINI, R. e RUAS, J. A. G. (2006). Forças atuantes na indústria de construção naval. Relatório de Pesquisa do Convênio Finep/Engenharia Naval. EPUSP, mimeo, setembro.

DORES, P. B.; LAGE, E. S. e PROCESSI, L. D. (2012). A retomada da indústria naval brasileira. BNDES 60 anos: perspectivas setoriais, v. 1, pp. 274-299.

FERRAZ, J. C. (1986). Determinants and consequences of rapid growth in the brazilian shipbuilding industry. Londres, Sussex.

FERRAZ, J. C. et al. (2002). Estudo da competitividade de cadeias integradas no Brasil: impactos das zonas de livre comércio. Unicamp/IE, dezembro.

FRASSA, J.; VERSINO, M.; JESUS, C. G. e GITAHY, L. M. (2011). El rol estatal en sectores estratégicos: la industria naval pesada en Argentina y Brasil. Revista de Historia Industrial Economia y Empresa, v.1, n. 47, pp. 151-181.

FURTADO, A. T. (2002). Mudança Institucional e Política Industrial no Setor Petróleo. Revista Com Ciência. Disponível em: http://www.comciencia.br/framebusca.htm. Acesso em: 12 out 2002.

(2005). Mudança institucional e política industrial no setor petróleo. Revista com Ciência, 2002. Disponível em: http://www.comciencia.br/framebusca.htm. Acesso em: 12 out.

FURTADO, A. T. et al. (2003). Política de compras da indústria do petróleo e gás natural e a capacitação dos fornecedores no Brasil: o mercado de equipamentos para o desenvolvimento de campos marítimos. In: Projeto CTPETRO/Tendência Tecnológicas. Rio de Janeiro.

IBGE - Instituto Brasileiro de Geografia e Estatística. (2016). Cidades. Disponível em: http://www. cidades.ibge.gov.br/v3/cidades/home-cidades. Acesso em: 2 abr 2016.

INDI (2010). Subsídios para a discussão sobre a atração de investimentos no setor de constução naval. Fiec. Ceará, ano 3, n. 5.

JESUS, C. G. e GITAHY, L. M. C. (2009). Transformações na indústria de Construção Naval Brasileira e seus impactos no mercado de trabalho (1997-2007). In: 10 CONGRESSO DE DESENVOLVIMENTO REGIONAL DE CABO VERDE, 15 CONGRESSO DA APDR - ASSOCIAÇÃO PORTUGUESA DE DESENVOLVIMENTO REgIONAL. Cidade da Praia - Cabo Verde. Actas Proceedings, pp. 3898-3916.

(2010). Indústria da construção naval, trabalho e desenvolvimento regional em Angra dos Reis no início do século XXI. In: XI SEMINÁRIO INTERNACIONAL DE LA RED IBEROAMERICANA DE INVESTIGADORES SOBRE GLOBALIZACIÓN Y TERRITORIO. Anais. Mendoza, Argentina, Cifot, v. 1.

JESUS, C. G. (2013). Retomada da indústria de construção naval brasileira: reestruturação e trabalho. Tese de Doutorado. Campinas, Universidade Estadual de Campinas. 
JESUS, C. G. (2016a). "Labour in the Brazilian Shipbuilding Industry: a contribution to an analysis on the recovery period". In: VARELA, R.; MURPHY, H. e VAN DER LINDEN, M. (orgs.). Shipbuilding and ship repair workers around the word. Chicago/Amsterdam, Chicago Press/Amsterdam University Press, v. 1, pp. 477-490.

(2016b). Notas sobre a desconcentração regional da indústria de construção naval brasileira no princípio do século XXI. RDE - Revista de Desenvolvimento Econômico, v. XVIII, pp. 685-703.

LACERDA, S. M. (2003). Oportunidades e desafios da construção naval. Revista do BNDES. Rio de Janeiro, BNDES, v. 10, n. 20, pp. 41-78.

LIMA, E. T. e VELASCO, L. O. M. (1998). Construção Naval no Brasil: existem perspectivas. Revista do BNDES, n. 10.

MARINS, C. (2009). Técnicas avançadas em planejamento e controle da construção naval. Tese de Doutorado. Rio de Janeiro, Universidade Federal do Rio de Janeiro.

MDICE (2002). Desenvolvimento de Ações de apoio à Cadeia Produtiva da Indústria Naval e Marinha Mercante. Brasília, Relatório, Ministério do Desenvolvimento, Indústria e Comércio Exterior, março.

NEGRI, J. A. de; KUBOTA, L. C. e TURCHI, L. (2009). Inovação e a Indústria Naval no Brasil. ABDI: estudos setoriais de inovação. Belo Horizonte.

NEIT/IE/UNICAMP (2002). Estudo da competitividade de Cadeias integradas no Brasil: impactos das zonas de livre comércio - cadeia Indústria Naval. Campinas, Nota técnica.

PASIN, J. A. B. (2002). Indústria Naval do Brasil: Panorama, Desafios e Perspectivas. Revista do BNDES. Rio de Janeiro, v. 9, n. 18, pp.121-148.

RAIS/MTE (2006-2014). Relatório de Informações Sociais. Brasília, MTE. Disponível em: http://www. rais.gov.br/sitio/index.jsf. Acesso em: 10 abr 2016.

(2006-2015). Relatório de Informações Sociais. Brasília, MTE.

ROSA, B. e ORDOÑEZ, R. (2016). Setor naval afunda: sem novos projetos da Petrobras, estaleiros começam a fechar as portas e demitem em massa. Márcia Foletto / Agência O Globo, 1/5/2016. Disponível em: http://oglobo.globo.com/economia/setor-naval-afunda-19205832\#ixzz4lkDJsto4. Acesso em: 20 jul.

SCHUTTE, G. R. (2012). Panorama do Pré-Sal: desafios e oportunidades. IPEA Texto para Discussão, 1791. Brasília.

SILVA, R. D. (2009). Estrutura Industrial e Desenvolvimento Regional no Estado do Rio de Janeiro (19902008). Tese de Doutorado. Campinas, Universidade Paulista de Campinas.

SINAVAL - Sindicato Nacional da Indústria de Construção e Reparação Naval e Offshore (2009). Cenário 2009. Rio de Janeiro. Disponível em: www.sinaval.org.br. Acesso em: 3 dez 2014.

(2011). Sinaval Informe Mensal: Novos Estaleiros em Implantação, maio.

(2012a). Visão Geral da Construção Naval Brasileira, março.

(2012b). Impactos na formação de RH nos estaleiros e a curva de aprendizado, agosto.

(2012c). Cenário do 4o trimestre de 2012 - Balanço Anual, dezembro.

(2014). Informes: emprego naval. Disponível em: www.sinaval.org.br. Acesso em: 3 dez 2014. 
SINAVAL - Sindicato Nacional da Indústria de Construção e Reparação Naval e Offshore (2015). Informe: Estaleiro BrasFELS relata avanços nas obras de plataformas e sondas. Disponível em: www.sinaval.org.br. Acesso em: 3 dez 2014.

(2016). Perdas da Petrobras com Sete Brasil chegam perto de R\$1 bilhão. Disponível em: www. sinaval.org.br. Acesso em: 25 de março de 2016.

SUZIGAN, W. (2000). Indústria brasileira: origem e desenvolvimento. São Paulo, Hucitec/Ed. Unicamp. (Economia \& Planejamento. Série Teses e Pesquisas).

UNCTAD (2014). World Maritime News. Disponível em: http://worldmaritimenews.com/ archives/174191/infographic-maritime-transport-in-2014/. Acesso em: 5 dez 2014.

Texto recebido em 6/set/2016

Texto aprovado em 7/nov/2016 